\title{
USE OF PHENOLS, PEROXIDASE, AND POLYPHENOLOXIDASE OF SEED TO QUANTIFY RESISTANCE OF COTTON GENOTYPES TO FUSARIUM WILT DISEASE
}

\author{
Amal A Asran and Heba I Mohamed* \\ Plant Pathology Research Institute, Agricultural Research Center, Giza, Egypt
}

Key words: Fusarium wilt, Biochemical markers, Cotton seed, Resistance

\begin{abstract}
A greenhouse test was conducted in 2011 and 2012 growing seasons at Giza Agricultural Research station to evaluate the reaction of six cotton genotypes to Fusarium wilt disease. The genotypes showed considerable variation in susceptibility to the disease (percentage of wilt incidence), which ranged from 32.24 to $88.0 \%$ In general, the genotypes could be divided into highly susceptible, susceptible, moderately susceptible, moderately resistant, and resistant. Data for wilt incidence and level or activity of some component biochemicals (phenols, peroxidase, and polyphenoloxidase) were introduced into a computerized linear regression analysis. The analysis constructed seven predictive models by using the biochemical components, singly or in combination, as biochemical predictors. It was evident that models nos. 1 and 5 were the best models for predicting incidence of Fusarium wilt. The superiority of these models was attributed to their high $\mathrm{R}^{2}$ value (0.668 and 0.814 , respectively) and the significance of their $\mathrm{F}$. values $(\mathrm{p}=$ 0.047 and $p=0.080$, respectively). The results of the present study suggest that phenols alone or both phenols and polyphenoloxidase in uninfected cotton seed, which may or may not take part of the Fusarium wilt resistance mechanisms, can use as biochemical markers to predict Fusarium wilt resistance.
\end{abstract}

Fusarium wilt is a destructive disease of cotton in many cotton-growing countries of the world including Australia, USA, Israel, Tanzania, and China, (Feng et al. 2000). The disease is caused by soil inhabiting fungus Fusarium oxysporum Schlect f.sp. vasinfectum (Atk). Snyd. and Hans. causing vascular wilt in susceptible cultivars (Watkins 1981, Chen et al. 1985, Hillocks 1992, Davis et al. 1996). The earliest report of the disease outside the USA came from Egypt (Fahmy 1927), where it spread rapidly with the release of Sakal cultivar during the 1920. Pathogenic variation within FOV, as we have demonstrated herein, is well documented in the literature (Bakry et al. 1958, Abd-Elsalam et al. 2009). Since then an extensive cotton-breeding program was initiated to develop cultivars highly resistant to the disease (Abd-Elsalam et al. 2009). The Egyptian race (race 3) of FOV has long been known in the Nile Valley, where it remains one of the most damping pathogen on G. barbadense cultivars (Watkins 1981, AbdElsalam et al. 2004). This race also attacks G. barbadense in the former Soviet Union (Watkins 1981) and Israel (Netzer et al. 1985).

Currently, all commercial cotton cultivars in Egypt are highly resistant to Fusarium wilt; however, the disease remains a potential threat to cotton production in Egypt because FOV is well established (Aly et al. 2000) and new races other than race 3 or new biotypes of the race may arise.

It has been suggested that a variety of substances contained in plant cells are involved in resistance or susceptibility to infection by pathogens. Among these are phenols, peroxidase, and polyphenoloxidase (Agrios 2005, Ashry and Mohamed 2011). These biochemical components (phenol, peroxidase and polyphenol oxidase) act as secondary metabolites and antioxidant enzymes.

*Author for correspondence: <hebaibrahim79@yahoo.com>. ${ }^{1}$ Department of Biological and Geological Science, Faculty of Education, Ain Shams University, Cairo, Egypt. 
The involvement of phenols as secondary plant metabolites in plant disease resistance is based on to large extent on their cytotoxicty. Phenolics seem to inhibit disease development through different mechanisms involving the inhibition of extracellular fungal enzymes (cellulases, pectinases, laccase and xylanase), inhibition of fungal oxidative phosphorylation, nutrient deprivation (metal complexation, protein insolubilisation), the inhibition of both spore germination and mycelial growth of different pathogenic fungi and antioxidant activity in plant tissues (Chérif et al. 2007).

Various antioxidant enzymes such as peroxidase (POX), superoxide dismutase (SOD), catalase (CAT), polyphenol oxidases (PPO) and ascorbate peroxidase (APX) participate in ROS metabolism during the pathogen attack. POX may be some of the elements of the defense systems that are stimulated in plants in response to pathogen infection like Fusarium oxysporum (Morkunas and Gemerek 2007). However, from practical standpoint, apart from peroxides (Reuveni et al. 1992) and amino acids (Aly et al. 2010), no attempts have been made to utilize these substances, in healthy genotypes, as biochemical markers to predict resistance to disease in breeding programs. Therefore, the main objective of the present study was to develop statistical models to predict wilt incidence on cotton genotypes by using the substance as biochemical predictors.

Isolation, purification and identification of Fusarium oxysporum Schlect $\mathrm{f}$. sp. vasinfectum (FOV) to form special is level of the isolates used in the present study were carried out at Cotton Pathology Section, Plant Path. Res. Inst., Agric. Res Cent., Giza. Substrate for growth of each isolate was prepared in $500 \mathrm{ml}$ glass bottles containing $50 \mathrm{~g}$ of sorghum grains and $40 \mathrm{ml}$ of tap water. Contents of bottles were autoclaved for $30 \mathrm{~min}$. Isolate and inoculums taken from one week old culture on PDA was aseptically introduced into the bottles and allowed to colonize sorghum for three weeks. The inoculums used in the present test for soil infestation was a mixture of equal amounts (w/w) of 30 isolates of FOV race 3. Autoclaved clay loam soil was infested with the mixture of isolates at the rate of $10 \mathrm{~g} / \mathrm{kg}$ of soil. Infested soil was dispensed in diameter $10 \mathrm{~cm}$ clay pots and these were planted with seeds of the tested genotypes (10 seeds/pots) and keep on greenhouse bench under a temperature ranged from $23 \pm 3$ to $33 \pm 2.5^{\circ} \mathrm{C}$. Percentage of infected seedlings, which showed any external or internal symptoms (Aly et al. 2000) was recorded 45 days after planting. The reactions of the genotypes to Fusarium wilt were evaluated twice. Cotton genotypes (Gassypium barbadense L.) used in the present study were obtained from Cotton Research Institute, Agric. Res. Cent., Giza. Random samples of seeds, taken from the same seeds used in planting the greenhouse experiment, were used for the chemical analysis, which was carried out as follows: soluble phenols in fresh samples were extracted according to Dihazi et al. (2003). Two grams of fresh sample were homogenized well in cold phosphate buffer (0.05 M at $\mathrm{pH}$ 6.5) and the homogenate was centrifuged at $1000 \mathrm{rpm}$ for $10 \mathrm{~min}$. The filtrate was made to a known volume and used to determine enzymes. Peroxidase (EC 1.11.1.7) and polyphenoloxidase (EC 1.14.18.1) was assayed following the method of Kar and Mishra (1976) with slight modification. The experimental design of the greenhouse experiment and the laboratory was a randomized complete block with five replicates (blocks) in the greenhouse experiment and three replicated in the laboratory tests. Analysis of variance (ANOVA) of the data was performed with the MSTATC software, DMRT was used to compare genotype means. Regression analysis was performed with a computerized program (SPSS Version 13).

External symptoms of Fusarium wilt were evident in the susceptible seedlings of the tested genotypes 20 days after planting. These seedlings were usually killed within 25 to 30 days after planting or they might survive showing external wilt symptoms on cotyledons. The symptoms were discrete area of vein discoloration in the cotyledonary leaves usually began at the margin, turned yellow or brown, eventually, the entire leaf wilted. A distinctive characteristic of Fusarium wilt is dark brown discoloration of the root and stem xylem. In the present study, we used rigorous 
criteria for disease rating. According to these criteria, the seedlings were considered healthy only if they were completely free of any internal and external symptoms. Thus the seedling if they showed internal discoloration even though they were considered susceptible was free of any external symptoms.

Environmental conditions in the greenhouse were favorable for unrestricted development of wilt fungus. The soil was sterile, temperature was optimal most of the time and the sterile soil was infested with different pathogenic isolates. Under these conditions, it is unlikely that any susceptible seedlings would have escaped detection in the test. In general, the tested genotypes could be divided into five groups, i.e. highly susceptible (HS), susceptible (S), moderately susceptible (MS), moderately resistant (MR) and resistant (R). This classification based on wilt incidence (the percentage of infected seedling/pot) (Table 1). Currently, due to the direction of wilt nurseries, screening of breeding materials under greenhouse conditions is the only reliable method in Egypt to distinguish the highly resistant Fusarium wilt genotypes. The test is time consuming and may be influenced by variability inherent in the experimental system (A.A. Aly, personal communication). The first symptoms of the disease appear on susceptible genotypes 20 days from planting date under very favorable environmental conditions and may require a longer period of time under less very favorable condition.

Table 1. Incidence of Fusarium wilt (\%) on six cotton genotypes and their disease categories under greenhouse conditions in Giza in 2011 and 2012 growing seasons.

\begin{tabular}{lcc}
\hline Genotype & Wilt incidence $^{\text {a }}(\%)$ & Disease category $^{\text {b }}$ \\
\hline $423 / 2002$ & $88.00 \mathrm{~A}$ & HS \\
$403 / 2002$ & $61.00 \mathrm{AB}$ & $\mathrm{S}$ \\
$494 / 2002$ & $54.66 \mathrm{~B}$ & MS \\
$401 / 2002$ & $48.12 \mathrm{~B}$ & MR \\
$405 / 2002$ & $42.00 \mathrm{~B}$ & MR \\
$427 / 2002$ & $32.24 \mathrm{~B}$ & $\mathrm{R}$ \\
\hline
\end{tabular}

${ }^{a}$ Wilt incidence is the percentage of infected seedling/pot. Each value is the mean of two growing seasons and each season included five replicates (pots). Means followed by the same letters are not significantly different $(\mathrm{p}<0.05)$ according to DMRT. ${ }^{\mathrm{b}}$ Disease categories are highly susceptible (HS), susceptible (S), moderately susceptible (MS), moderately resistant (MR) and resistant (R). This classification based on wilt incidence (the percentage of infected seedling/pot).

Therefore, reliable method, either alternative or complementary to the greenhouse test, is required for identification of the Fusarium-wilt highly resistant genotypes. This method should meet two requirements. It should be independent of the pathogen, and should reflect the genetic differences among genotypes. The biochemical components of cotton seeds (Table 2) may meet these requirements for several reasons. The increased levels of peroxidase activity in melon genotypes play an important role in the induction of resistance to Fusarium wilt disease (Madadkhah et al. 2012). The involvement of these components in resistance or susceptibility is well documented in the literature as previously mentioned in the introduction. The occurrence of each, except phenols varied with the cultivars (Table 2). They can be determined rapidly and with small amounts of cotton seeds. Therefore, large number of genotypes can be tested without sacrificing the seeds.

Data for wilt incidence and level or activity of each component were entered into a computerized linear regression analysis. The analysis constructed seven predictive models by using the biochemical components, singly or in combination, as biochemical predictors (Table 3). 
It is evident that models nos. 1 and 5 are the best models for predicting incidence of Fusarium wilt. The superiority of these models is attributed to their high $\mathrm{R}^{2}$ value and the significance the of their F. values. Models 4 and 7 also show high $\mathrm{R}^{2}$ value; however, they were excluded due to non significant values. One should keep in mind that the significant r-values of models 1 and 5 should be interpreted with caution (Gomez and Gomez 1984) because significant correlation does not necessarily imply causation.

Table 2. Determination of levels and activities of biochemical components in healthy seeds of six cotton genotypes.

\begin{tabular}{lccc}
\hline & \multicolumn{3}{c}{ Component } \\
\cline { 2 - 4 } Genotype & Phenols (mg/g FW) & $\begin{array}{c}\text { Peroxidase } \\
\text { (activity /h/g FW) }\end{array}$ & $\begin{array}{c}\text { Polyphenoloxidase } \\
\text { (activity/h/g FW) }\end{array}$ \\
\hline $401 / 2002$ & $2.01^{\mathrm{a}} \mathrm{A}$ & $6.49 \mathrm{AB}$ & $11.81 \mathrm{CD}$ \\
$427 / 2002$ & $1.68 \mathrm{~A}$ & $7.42 \mathrm{AB}$ & $20.68 \mathrm{AB}$ \\
$403 / 2002$ & $1.79 \mathrm{~A}$ & $9.92 \mathrm{~A}$ & $23.38 \mathrm{AB}$ \\
$405 / 2002$ & $1.76 \mathrm{~A}$ & $2.58 \mathrm{~B}$ & $7.17 \mathrm{D}$ \\
$494 / 2002$ & $1.79 \mathrm{~A}$ & $3.86 \mathrm{AB}$ & $17.43 \mathrm{BC}$ \\
$423 / 2002$ & $2.22 \mathrm{~A}$ & $9.23 \mathrm{~A}$ & $26.35 \mathrm{~A}$ \\
\hline
\end{tabular}

${ }^{a}$ Each value is the mean of three replicates. Within a column, means followed by the same letter(s) are not significantly different $(\mathrm{p}<0.05)$ according to Duncan's multiple range test. The letter A, B, AB, BC and D means that the same letter means that there are non significantly different between the different genotypes. This table means the amount and the activity of these different components in healthy seeds of cotton genotypes. The seeds of the resistance cotton genotypes (423/2002) contain a large amounts of the biochemical components.

Table 3. Linear regression models that describe the relationship between some biochemical components $\left(X_{s}\right)$ in healthy seeds of six cotton genotypes and Fusarium wilt $(y)$ on these genotypes.

\begin{tabular}{|c|c|c|c|c|c|c|}
\hline $\begin{array}{l}\text { Independent variable (s) } \\
\text { or Predictor(s) }\end{array}$ & $\begin{array}{l}\text { Mod } \\
\text { no. }\end{array}$ & $\begin{array}{l}\text { Linear regression } \\
\text { model }\end{array}$ & $\mathrm{r}^{\mathrm{a}}$ & $\mathrm{R}^{2 \mathrm{~b}}$ & F. value & $\mathrm{P}>\mathrm{F}$ \\
\hline *Phenols (X1) & 1 & $Y=-93.24+78.64 X 1$ & 0.818 & 0.668 & 8.066 & 0.047 \\
\hline Peroxidase (X2) & 2 & $Y=25.19+4.18 \mathrm{X} 2$ & 0.567 & 0.321 & 1.894 & 0.241 \\
\hline Polyphenoloxidase (X3) & 3 & $Y=25.09+1.64 X 3$ & 0.616 & 0.380 & 2.452 & 0.192 \\
\hline X1and X2 & 4 & $\mathrm{Y}=-89.72+67.9 \mathrm{X} 1+2.38 \times 2$ & 0.872 & 0.760 & 4.761 & 0.117 \\
\hline * X1and X3 & 5 & $Y=-89.76+66.64 \times 1+1.07 \times 3$ & 0.902 & 0.814 & 6.555 & 0.080 \\
\hline $\mathrm{X} 2$ and $\mathrm{X} 3$ & 6 & $\mathrm{Y}=25.11-0.01 \mathrm{X} 2+1.65 \mathrm{X} 3$ & 0.616 & 0.380 & 0.920 & 0.488 \\
\hline $\mathrm{X} 1, \mathrm{X} 2$ and $\mathrm{X} 3$ & 7 & $Y=-90.61+68.39 X-2.04 \times 2+1.73 \times 3$ & 0.908 & 0.825 & 3.147 & 0.250 \\
\hline
\end{tabular}

*The best regression models for quantifying incidence of Fusarium wilt on cotton genotypes. ${ }^{\mathrm{a}}$ Linear correlation coefficient. ${ }^{\mathrm{b}}$ Coefficient of determination.

In conclusion, the results of the present study suggest that phenols alone or both phenols and polyphenoloxidase in uninfected cotton seeds can be used as biochemical markers to predict Fusarium wilt resistance. In practical terms, our results mean that a primary selection to eliminate susceptible genotypes can be made before planting. In this primary selection, only genotypes with low levels of phenols (in case of using model no. 1) or with low levels of phenols and low activity of polyphenol oxidase (in case of using model no. 5) would be retained for further evaluation under greenhouse conditions and thereby decrease the time and effort necessary for the development of resistant genotypes in breeding programs. 


\section{Acknowledgement}

This work was supported by grant from Agricultural Research Centre, Giza, Egypt.

\section{References}

Abd-Elsalam KA, Omar MR, Migheli Q and Nirenberg HI 2004. Genetic characterization of Fusarium oxysporum Schlect f. sp. vasinfectum isolates by random amplification of Polymorphic DNA (RAPD) and amplified fragment length polymorphism (AFLP). J. Plant Dis. Prot. 111: 534-544.

Abd-Elsalam KA, Omar MR, Asran AA and Aly AA 2009. Differential interaction between cotton genotypes and isolates of Fusarium oxysporum f. sp. vasinfectum. Arch. Phytopathol. Plant Prot. 42: 464-473.

Agrios GN 2005. Plant Pathology, $5^{\text {th }}$ Ed. Elsevier Academic Press, San Diego, California. p. 384.

Aly AA, Eisa HA, Mansour MTM, Zayed SME and Omar MR 2000. Resistances to Fusariums wilt disease in families of some commercial cotton cultivars. pp. 375-384. In Proceedings ${ }^{2}$ Conf. Egypt. Phytopathol. Soc. Giza.

Aly AA, Hussein EM, Omar MR and Abd-Elsalam KA 2010. Effects of amino acids in cotton seeds on the resistance to Fusarium wilt of cotton. Allelopathy J. 26: 83-90.

Ashry NA and Mohamed HI 2011. Impact of secondary metabolites and related enzymes in flax resistance and or susceptibility to powdery mildew. World J. Agri. Sci. 7(1): 78-85.

Bakry MA, Sakre AH, Kassab OA and Rizk RH 1958. Infection of some cotton varieties with Fusarium and the possibility of the existence of strains of fungus. Proc. $2^{\text {nd }}$ Cotton Conf. (in Arabic). Giza, Egypt.

Chen Q, X Ji and W Sun 1985. Identification of races of cotton wilts Fusarium in China. J. Agric. Sci. China 6:1-6.

Chérif M, Arfaoui A and Rhaiem A 2007. Phenolic compounds and their role in bio-control and resistance of chickpea to fungal pathogenic attacks. Tunisian J. Plant Protect. 2(1): 7-21.

Davis RD, Moore NY and Kochman JK 1996. Characterization of a population of Fusarium oxysporum Schlect f. sp. vasinfectum causing wilt of cotton in Australia. Aust. J. Agric. Res. 47: 1143-1156.

Dihazi AD, Jaiti F, Zouine J, El-Hassni M and El-Hadrami I 2003. Effect of salicylic acid on phenolic compounds related to date palm resistance to Fusarium oxysporum f. sp. albedinis. Phytopathol. Mediter. 42: 9-16.

Fahmy T 1927. The Fusarium wilt disease of cotton and its control. Phytopathol. 17: 749-767.

Feng J, Wen S, Leiyan S, Ma C, Feng J, Sun WJ and Shi CLY 2000. RAPD analysis of physiological races of Fusarium oxysporum Schlect f.sp. vasinfectum in china. Mycosystema 19: 45-50.

Gomez KA, Gomez AA 1984. Statistical Procedures for Agricultural Research. $2^{\text {nd }}$ Ed. John Wiley and Sons Ltd, New York, p. 680.

Hillocks RJ 1992. Fusarium wilt. In: Cotton Diseases. R.J. Hillocks (ed.). Melkshma, UK; Redwood Press ltd, 127-160.

Kar M and Mishra D 1976. Catalase, peroxidase and polyphenoloxidase activity during leaf Senescence. Plant Physiol. 57: 315-349.

Madadkhah E, Lotfi M, Nabipour A, Rahmanpour S, Banihashemi Z, Shoorooei M, 2012. Enzymatic activities in roots of melon genotypes infected with Fusarium oxysporum f. sp. melonis race 1. Scientia Hort. 135: 171-176.

Morkunas I and Gemerek J 2007. The possible involvement of peroxidase in defense of yellow lupine embryo axes against Fusarium oxysporum. J. Plant Physio. 164: 497-506.

Netzer D, Ta Y, Marani A and Weintall C 1985. Resistance of interspecific hybrids (Gassypium barbadense containing G.harknessii cytoplasm) to Fusarium wilt. Plant Dis. 69: 312- 313.

Reuveni R, Shmoni M, Karchi Z and Kuc J 1992. Peroxidase activity as a biochemical marker for resistance of muskmelon (Cucumis melo) to Pseudopernospora cubensis. Phytopathol. 82: 749-753.

Watkins GM 1981. Compendium of cotton Diseases. The Amer. Phytopathol. Soc. St. Paul, MN.87P. 